\title{
Erratum: Characterization of a GaAs photon-counting detector for mammography
}

\author{
Bahaa Ghammraoui, ${ }^{a}{ }^{a} *$ Spyridon Gkoumas, ${ }^{b}$ and Stephen J. Glick \\ ${ }^{a}$ U.S. Food and Drug Administration, Office of Science and Engineering Laboratories, \\ Center for Devices and Radiological Health, Silver Spring, Maryland, United States \\ ${ }^{\mathrm{b} D E C T R I S ~ L t d ., ~ B a d e n, ~ S w i t z e r l a n d ~}$
}

[DOI: 10.1117/1.JMI.8.4.049801]

This article [J. Med. Imag. 8(3), 033504 (2021) doi: 10.1117/1.JMI.8.3.033504] was originally published in Vol. 8 Issue 3 of the Journal of Medical Imaging on 22 June 2021, with an incorrect image in Fig. 6 (a duplicate of Fig. 3). The article was republished with the correct image in Fig. 6 on 24 June 2021.

*Address all correspondence to Bahaa Ghammraoui, bahaa.ghammraoui@fda.hhs.gov 